\title{
Tecendo vias para 0 entendimento do projeto para uma psicologia científica
}

\author{
Weaving ways to understand the project for a scientific psychology
}

\section{Sissi Vigil Castiel' e Pâmela Soares Bratkowski}

Resumo: Dada a relevância para a psicanálise do texto freudiano Projeto para uma Psicologia Científica (1985-1996), este artigo se propõe a tecer uma via de leitura por meio do ponto de vista econômico da metapsicologia. Para este fim, partiu-se de uma revisão narrativa da literatura e foram utilizados textos clássicos de Freud e de autores contemporâneos que dissertam sobre o tema e contribuem para o entendimento do Projeto. Neste artigo, serão enfatizados, particularmente, os conceitos relevantes para o entendimento da parte I - O esquema geral, na qual Freud parte de dois teoremas principais, a teoria dos neurônios e a concepção quantitativa, que se conectam e implicam no funcionamento psíquico. Além disso, um dos propósitos deste artigo também é demonstrar que os elementos conceituais do Projeto têm um estatuto de origem de conceitos psicanalíticos posteriores que já faziam parte do pensamento freudiano em 1895, tais como representação, pulsão, sexualidade, pensamento e linguagem.

Palavras-chave: Neurônios; Quantidade; Princípio de constân-
Abstract: Given the relevance for the psychoanalysis of the Freudian text Project for a scientific psychology (1985-1996), this article proposes to weave a way of reading through the economic point of view of metapsychology. To this end, a narrative review of the literature was started and classic texts by Freud and contemporary authors were used to lecture on the theme and contribute to the understanding of the Project. In this article, it will be emphasized, in particular, the relevant concepts for the understanding of part I - The general scheme, in which Freud starts from two main theorems, the theory of neurons and the quantitative conception, which are connected and imply psychic functioning. In addition, one of the purposes of this article is also to demonstrate that the conceptual elements of the Project have a status of origin of later psychoanalytic concepts that were already part of Freudian thought in 1895, such as representation, drive, sexuality, thought and language.

Keywords: Neurons; Quantity; Principle of constancy. cia.

\footnotetext{
1 Psicanalista. Doutora em Psicologia pela Universidade Autônoma de Madri. Presidente da Sigmund Freud Associação Psicanalítica. Sócia efetiva da Sociedade de Psicologia do Rio Grande do Sul. E-mail: sissi.castiel@gmail.com

2 Psicóloga. Diretora científica da Sociedade de Psicologia do Rio Grande do Sul. Psicanalista em Formação pela Sigmund Freud Associação Psicanalítica. E-mail: pamelasoaresb@gmail.com
} 


\section{Introdução}

Freud, em 1895, influenciado por sua formação médica e pela relação com seus colegas de profissão, estava ocupado em explicar a psicologia sob o ponto de vista da neurologia e poder comprovar suas teses cientificamente. Para isso, ele queria demonstrar o funcionamento mental por meio de uma abordagem quantitativa e levar a psicopatologia a inspirar a psicologia geral.

Antes e durante essa data, Freud estava ocupado com seus estudos sobre a neurose, principalmente em relação à histeria e à neurose obsessiva. Seu primeiro trabalho publicado, que dá início à psicanálise, foi Estudos sobre a histeria (1893/1895-1996) e foi escrito junto com Breuer. Os estudos que o levaram a escrever o Projeto para uma psicologia cientíica (1985-1996) foram desenvolvidos ao longo de muitos anos e fizeram-no deparar-se com elementos que the permitiram concluir sua teorização.

Em 06 de agosto de 1895, Freud escreveu a Fliess - para quem enviava muitas cartas sobre suas ideias entre os anos de 1887 e 1904 - que tinha chegado a uma compreensão da defesa patológica e de importantes processos psicológicos (Masson, 1986). No entanto, em seguida, no dia 16 de agosto, ele escreveu novamente ao amigo informando que teve uma experiência ruim com seus estudos, que não tinha mais fôlego devido à sobrecarga de trabalho eque havia perdido o interesse no assunto (Masson, 1986). Ele inclusive referiu que abandonou por um tempo suas ideias e disse preferir jogar boliche e fazer outras atividades em vez de escrever sobre elas (Masson, 1986).

No mês de setembro do mesmo ano, Freud visitou Fliess em Berlim para conversar acerca de suas ideias, abordando sobre os neurônios terem a capacidade de dotar quantidades de energias e sobre os destinos que elas teriam para o funcionamento psíquico (Gay, 1923-2012). Parece que a conversa com Fliess Ihe gerou grandes ideias, pois iniciou a escrita do Projeto (1985-1996) no trem durante a viagem de retorno à sua casa e enviou para seu amigo no dia 08 de outubro (Gay, 1923-2012).

No entanto, Freud não gostou das ideias desenvolvidas em seu trabalho e deixou-o de lado. Além disso, extinguiu a cópia do trabalho que havia ficado consigo enunca mais tocou no assunto em suas obras e cartas. Por este motivo, o Projeto (1985-1996) ficou por muitos anos esquecido e não mencionado. Contudo, depois da morte de Freud, a Princesa Marie Bonaparte, em 1937, conseguiu recuperar a cópia que Freud tinha enviado para Fliess junto com outras cartas a ele enviadas (Castiel et al., 2009). Dessa forma, foi graças à Princesa Marie Bonaparte que hoje temos acesso a muitas das cartas enviadas a Fliess por Freud, e o Projeto (1985-1996) foi descoberto.

0 texto mencionado foi publicado pela primeira vez em alemão no ano de 1950. Este texto é extremamente valorizado por alguns psicanalistas e desvalorizado por outros, visto que muitos acreditam que vários conceitos psicanalíticos são mencionados por Freud neste trabalho, e outros o consideram pré-psicanalítico (Garcia-Roza, 1984).

Freud dá início ao Projeto (1985-1996) explicando que sua intenção é estruturar uma psicologia que seja uma ciência natural. Peter Gay (1923-2012) afirma que os estudos freudianos nesse texto são coerentes com o trabalho dos grandes positivistas da época, ainda que as sementes de conceitos psicanalíticos posteriores já estejam presentes. Cabe sinalizar que, nessa época, Freud era influenciado pelas ideias de Theodor Meynert, Helmholz, Brücke, Fechner, Johann Friedrich Herbart e Sigmund Exner (Garcia-Roza, 1984). Entendemos que, mesmo que o pensamento de Freud estivesse de acordo com os ideais cientificistas daquele momento, a estruturação do Projeto (1985-1996) permite ir muito além disso, na medida em que contém a origem de suas ideias sobre o funcionamento psíquico considerando-o constituído de forma heterogênea, e a essência da subjetividade sendo composta como desejante. Nesse texto, Freud âncora seus conceitos posteriores de representação, pulsão, sexualidade, pensamento e linguagem (Castiel, 2019).

0 Projeto (1985-1996) é dividido em três partes, sendo a primeira um esquema geral do funcionamento psíquico, a segunda dedicada à psicopatologia, em especial a histeria, e a terceira, por fim, uma tentativa de representar os processos psíquicos normais. Segundo Garcia-Roza (1984), o Projeto (1985-1996) "é um modelo explicativo que não supõe qualquer sentido denotativo do real. Esse modelo é tomado de empréstimo da física, particularmente à termodinâmica" (p. 46). 0 mesmo autor ressalta que esse não é um trabalho escrito a partir de observações e experimentos; por esse motivo, éfundamentalmente hipotético e não é uma tentativa de explicação do funcionamento do aparelho psíquico em bases anatômicas, "mas, ao contrário, implica uma renúncia à anatomia e a formulação de uma metapsicologia" (Garcia-Roza, 1984, p. 47).

Existem muitas vias pelas quais o Projeto (1985-1996) pode ser trabaIhado, e uma delas é o ponto de vista econômico, tendo em vista seu estatuto na obra de Freud. A hipótese econômica está presente do início ao fim dos textos de Freud e tem um lugar de destaque (Castiel, 2019). É definida pelo teórico como 0 aspecto que trata sobre o destino das quantidades de energia e consiste em tomar em consideração os investimentos na sua mobilidade e variações para poder estimar sua grandeza relativa (Freud, 1915-1996). 0 tema foi trabalhado primeiramente em Comunicação Preliminar (1893-1996), em conjunto com Breuer, e, posteriormente, no Projeto (1985-1996), como forma de explicar o funcionamento psíquico em geral. Neste artigo, escolhemos trabalhar os temas que se referem à economia psíquica, devido à sua relevância para a metapsicologia e para a clínica psicanalítica.

\section{Método}

Este artigo foi escrito por duas sócias da Sociedade de Psicologia do Rio Grande do Sul a partir dos estudos sobre o texto Projeto (1985-1996) de Freud. 0 formato escolhido para o estudo do tema foi o de revisão narrativa da literatura, por meio de textos clássicos de Freud e de autores contemporâneos.

\section{Os dois teoremas principais}

Freud, no Projeto (1985-1996), representa os processos psíquicos como estados quantitativamente determinados, dotados de partículas materiais especificáveis a partir de dois teoremas principais: a concepção quantitativa e a teoria dos neurônios. Foi a partir da análise das neuroses - e suas ideias excessivamente intensas - que Freud pôde observar e fundamentar suas teorias. Com base nisso, generalizou a ideia de uma quantidade (Q) em estado fluente como parte do funcionamento psíquico em geral. Ele se ocupou da quantidade de energia, da direção e do impacto dessa energia que circula sobre os neurônios. Portanto, além de propor - baseado na segunda teoria da termodinâmica - que havia um fluxo contínuo de energia circulando no sistema nervoso, também considerou que essa circulação ocorreria em cadeias de neurônios.

Com relação ao primeiro teorema, refere que a tendência primordial da atividade neurônica é a descarga das quantidades de energia, o que consistiria 
no princípio da inércia. Um sistema nervoso primário faz uso da Q recebida para descarregá-la nos mecanismos musculares e, desse modo, manter-se livre de estímulos. No entanto, desde o início, o princípio de inércia é rompido por diversas circunstâncias, pois, na medida em que aumenta a complexidade interior do organismo, o sistema nervoso passa a receber estímulos endógenos, que também têm que ser descarregados, como a fome, a respiração e a sexualidade. Destes, a contrário do que faz com os estímulos externos, 0 organismo não pode fugir, pois eles cessam apenas mediante condições que se realizam no mundo externo, como a nutrição, por exemplo. Com isso, o sistema nervoso se vê obrigado a abandonar sua tendência inicial de inércia e deve tolerar um acúmulo de Q suficiente para satisfazer as exigências desses estímulos, que dependem de uma presença alheia para que cessem. Isso estabelece uma segunda tendência do sistema nervoso, que é a de manter a Q no mais baixo nível possível e resguardar-se contra qualquer aumento dela, o que consistiria no princípio de constância.

Desse outro ponto de vista, a inércia e a constância se articulam de forma diferente com o prazer. Na primeira, a descarga total de energia poderia ser igualada a uma busca de prazer total, ou seja, prazer é ausência de excitações. Já na constância, prazer não está ligado a uma descarga total de excitação e relaciona-se à satisfação das necessidades para as quais se precisa guardar um pouco de energia. Essa ideia é retomada muitos anos mais tarde, em Além do Princípio do Prazer (1920-1996), quando Freud refere que"o aparelho mental se esforça por manter a quantidade de excitação nele presente tão baixa quanto possível, ou, pelo menos, para mantê-las constantes" (p. 18). Nesse último texto, a descarga total de energia está ligada à morte e ao princípio de nirvana. Já o prazer está relacionado à vida e está ligado ao princípio de constância, portanto, comporta excitações.

0 segundo teorema principal se refere à teoria dos neurônios, que se estabelece em conexão com a teoria da $Q$, na qual se chega à ideia de um neurônio catexizado com determinada $Q$ em alguns momentos. Freud (1985-1996) se ocupa de distinguir os neurônios para explicar como é feita a condução da quantidade de energia e esclarece que possuem funções distintas, mas são constituídos de forma similar e estão em contato recíproco. Eles terminam uns sobre os outros e neles se acham estabelecidas determinadas vias de condução. Além disso, possuem ramificações de vários calibres e são divididos em próprios para receber estímulos, próprios para transmiti-los e próprios para conduzir os conteúdos da consciência, sendo eles $\Phi, \Psi$ e $\omega$.

Segundo 0 autor, os neurônios $\Phi$ são os que recebem os estímulos externos e não retêm as quantidades recebidas, portanto, são permeáveis à passagem de energia e imutáveis, na medida em que a passagem da $Q$ não modifica sua estrutura. Já os neurônios $\Psi$ são aqueles que recebem menor quantidade de energia, pois não estão em contato direto com o mundo externo. A $Q$ chega a $\Psi$ por meio de $\Phi$ ou do interior do organismo. Esses neurônios são impermeáveis à passagem de $Q$ e mutáveis, uma vez que conservam a energia dentro deles.

Todos os neurônios, segundo Freud (1985-1996), são compostos por barreiras de contato, que se opõem ao livre escoamento de quantidades de energia. Porém, devido à intensidade da quantidade de energia que chega aos neurônios $\$$, a resistência destes é quase nula na medida em que recebem os estímulos do mundo externo, e, com isso, são uma forma de anteparo para que as quantidades de energia que chegam em $\Psi$ sejam pequenas.

Freud (1985-1996) refere que há uma terceira classe de neurônios, movida por quantidades ainda mais reduzidas de energia, que são os neurônios $\omega$. Estes são excitados junto com a percepção e apropriam-se do período, entendendo-se este como o elemento de tempo e percurso da $Q$ no sistema nervoso. Portanto, essa classe de neurônios relaciona-se à qualidade no sentido das sensações que as ocorrências psíquicas causam.

Os neurônios w, segundo Freud (1985-1996), são "incapazes de receber 0 , mas, em compensação, se apropriam do período de excitação e, nesse estado de serem afetados por um período enquanto são enchidos de um mínimo de quantidade de energia, constituem a base fundamental da consciência" ( $p$. 362). A consciência - como as qualidades do sentir - relacionam-se prioritariamente com as sensações de prazer e desprazer. No entanto, as ocorrências psíquicas são, em sua maior parte, inconscientes, e ocorrem principalmente em $\Psi$, não necessariamente chegando a $\omega$. Com isso, Freud faz ver que os processos psíquicos se dão prioritariamente em $\Psi$, e a consciência é apenas um desdobramento desses processos, que podem ou não ocorrer. Portanto, ainda que a teorização do sistema inconsciente seja formulada por ele cinco anos mais tarde, sua ideia já está claramente em seu pensamento nesse texto.

É importante salientar que, nesse momento, Freud não está ocupado com uma visão tópica dos processos psíquicos, ou seja, com a localização onde eles ocorrem. Sua intenção principal é demonstrar economicamente as consequências psíquicas dos percursos das $Q$ nos distintos neurônios. A preocupação tópica ocupará o pensamento de Freud mais tarde, em 1900, no capítulo 7 de A Interpretação dos Sonhos (1900-1996). Ainda que Freud tenha desistido do Projeto, a conjunção desses dois textos dá início à metapsicologia.

\section{O funcionamento do sistema}

Um dos grandes temas do Projeto de Freud é que o ser humano, no início, é desamparado para lidar com as quantidades de energia que ingressam nele de dentro e de fora. Justamente, a articulação entre os dois teoremas principais éa de que existem diferentes neurônios que dão conta do ingresso e da tramitação da energia no sistema nervoso, pois as energias ingressam de fora e de dentro. Dos estímulos externos se pode fugir, mas diante dos estímulos internos, a fuga não é uma possibilidade. Assim, Freud (1985-1996) diz que o enchimento dos neurônios $\Psi$ terá como resultado uma propensão à descarga pela via motora. Contudo, nenhuma descarga dessa espécie pode levar ao alívio de um estímulo endógeno, visto que o estímulo continua a ser recebido, e se restabelece a tensão em $\Psi$. Nesse caso, a estimulação só é capaz de ser abolida por meio de uma intervenção que suspenda provisoriamente a descarga de $Q$ no interior do corpo, e uma intervenção dessa ordem requer uma alteração no mundo externo. 0 organismo humano é, a princípio, incapaz de realizar essa tarefa. Essa só se efetua por meio da assistência alheia, quando uma pessoa é atraída para o estado em que se encontra a criança. Ainda que a tendência inicial seja se desfazer da Q, o que representaria ausência de excitação, é indispensável retê-la como parte importante do processo de chamamento do outro para a satisfação das necessidades. A partir disso, o sistema nervoso se constitui.

Freud (1985-1996) afirma que"0 desamparo humano é a fonte primordial de todos os motivos morais"(p. 370). Portanto, o outro se torna indispensável como aquele capaz de realizar uma ação que finalize com esse estado de tensão. Esta formulação freudiana implica a ideia de que, se o desamparo humano é a fonte de todos os motivos morais, é preciso reter energia dentro de si para chamar o outro - fala no choro como uma forma de chamamento. Dessa forma, a visão de Freud é de que o intersubjetivo é indispensável para a formação da subjetividade, além do intrapsíquico. 
A ação realizada pelo outro é denominada por Freud (1985-1996) de ação específica, colocando em evidência a ideia de que esse não é um ato qualquer, mas, sim, aquele que coloca fim à necessidade, gerando, com isso, uma experiência de satisfação. Esta última tem consequências decisivas para o desenvolvimento das funções individuais, segundo Freud: elimina-se a urgência que causa desprazer, produz-se a catexização dos neurônios que correspondem à percepção do objeto e também chegam as informações sobre os movimentos reflexos que se seguem à ação específica, estabelecendo-se, assim, uma facilitação entre essas catexias e os neurônios nucleares de $\Psi$. Destaca-se que estes são elementos centrais do pensamento freudiano no Projeto (1985-1996) na medida em que a experiência de satisfação deixará uma marca de algo que se quer repetir. Isso coloca o desejo ${ }^{3}$ como ponto central da constituição subjetiva no pensamento freudiano desde 1895.

Além disso, a experiência de satisfação cria uma marca - uma imagem mnêmica - do objeto que realizou a ação específica. Percebe-se que quando Freud fala da imagem mnêmica do objeto, está colocando em pauta duas questões fundamentais do que constituirá sua metapsicologia, sendo estas a memória e a representação, na medida em que a lembrança e o desejo de atrair 0 objeto que realiza a ação específica proporcionam uma organização psíquica, já que cria uma tendência à busca de um objeto. Esse é o fundamento do princípio do prazer como o princípio que rege o inconsciente e que será formulado por ele em 1900 e possibilitará que, mais tarde, em 1920, possa pensar sobre as falhas psíquicas decorrentes da não existência desse princípio como tendência à organização.

A marca da imagem mnêmica do objeto implica que um novo estado de tensão "resulte em uma atração positiva para o objeto desejado, ou, mais precisamente, para sua imagem mnêmica" (Freud, 1895-1950, p. 374). Portanto, para Freud, a catexização da imagem mnêmica do objeto resulta, primeiramente, na alucinação dele, independente da sua presença na realidade. Ou seja, a lembrança agradável do objeto é mais poderosa do que uma simples percepção. Em consequência disso, é necessário que o psiquismo consiga ser capaz de distinguir entre a percepção do objeto real e a sua representação, pois a catexização da imagem do objeto desejado sem a sua presença levaria ao desprazer (Castiel et al., 2009).

Por outro lado, Freud (1985-196) fala da experiência de dor que ocorre quando há um grande aumento de $Q$ em $\Psi$, que é sentido como desprazer por $\omega$. Com isso, há uma propensão à descarga, o que leva a uma facilitação entre essa última e a imagem mnêmica do objeto que acentua a dor. Se a imagem mnêmica deste objeto - sentido como hostil - é recatexizada pela percepção dele, surge um estado de desprazer e a tendência à descarga, que corresponde à experiência da dor.

A experiência de satisfação e a experiência de dor têm em comum 0 aumento de $Q$ em $\Psi$ que provocam. № caso da dor, pela liberação súbita e, no caso do desejo, por somação. Ambos estados deixam atrás de si motivações compulsivas em favor dessa passagem, que constitui uma facilitação. 0 estado de desejo leva à atração positiva pela imagem mnêmica do objeto que realiza a ação específica e a dor leva à repulsa por manter catexizada a imagem mnêmica do objeto hostil. Este último processo constitui a defesa primária ou o recalcamento - 0 abandono mais rápido possível da catexia do objeto hostil. Pensamos que, dessa forma, Freud descreve a essência do que constitui o recalcamento, a não catexização das representações do objeto.
Dentro da parte II do Projeto (1985-1996), que diz respeito à psicopatologia e não será abordada neste texto, Freud se refere ao recalcamento na neurose como um processo distinto desse descrito como defesa primária, na medida em que a defesa patológica inclui a formação de sintomas, descrita por ele através do caso Emma.

A atração de desejo e de defesa primária produzem facilitações sistemáticas de $Q$ em certos neurônios do núcleo de $\Psi$. Isso tem como consequência que um grupo de neurônios ficará catexizado constantemente e, desse modo, atende ao funcionamento da função secundária do psiquismo - a constância. Esse grupo de neurônios catexizados constantemente forma uma organização no sentido do direcionamento das Q e chama-se Ego. Essa organização deve ser definida, segundo Freud (1985-1996), como a totalidade das catexias $\Psi$ existentes em determinado momento, nas quais há uma porção permanente e outra variável. Este ego do Projeto (1985-1996) "nada tem a ver com o ego do sujeito" (Garcia-Roza, 1984, p. 56). Por outro lado, Freud descreve o ego em Sobre o Narcisismo: uma introdução (1914-1996) como um espaço de contenção psíquica das excitações do corpo em uma unidade. A partir da identificação primária, o ego é uma matriz inicial na qual estão em destaque a assunção de uma imagem corporal e a capacidade psíquica de vinculação da energia e contenção. Nesse sentido, o ego do Projeto (1985-1996) parece ser a semente da postulação de 1914 (Castiel, 2019).

A organização do ego funcionaria da seguinte forma: uma Q que rompe no neurônio continuaria na direção da barreira de contato mais facilitada, ou seja, as Q se distribuem na direção inversa das resistências das barreiras de contato. Dessa forma, quando uma $\mathrm{Q}$ incidir sobre uma barreira de contato cuja resistência for superior a ela, não passará por esse ponto. Assim, o curso adotado pela $Q$ dependerá das intensidades das facilitações. Se um neurônio adjacente estiver catexizado simultaneamente, isso atua como uma facilitação temporária das barreiras de contato, modificando o curso da Q, que, em caso contrário, tomaria direção da única barreira de contato facilitada. Esses investimentos alternativos - na forma de catexias colaterais - constituem-se em recursos para lidar com os excessos de Q que chegam a $\Psi$ e são uma inibição para a passagem de Q. Uma inibição desse tipo é uma vantagem decisiva para $\Psi$, pois, considerando-se a imagem mnêmica do objeto hostil, haveria consequentemente uma liberação de desprazer. Com a ação inibitória das vias colaterais, a liberação do desprazer fica reduzida, e o sistema nervoso é poupado sem grandes danos de um aumento e descarga de Q. Sendo assim, Freud (1985-1996) refere que essa organização (o ego) também auxilia na diferenciação entre o objeto real e a alucinação (estados de desejo), uma vez que inibe a passagem de excitação que conduziria ao desprazer (experiência de dor) por dispersá-las através da formação de neurônios adjacentes catexizados.

Disso se conclui que a contenção do livre escoamento das excitações "transforma o estado de pura dispersão em estados de integração ou organizações parciais" (Castiel et al., 2009, p. 43). A questão da contenção das excitações é um tema caro à teoria econômica de Freud, que tem um lugar especial no Projeto (1985-1996) e, novamente, terá em Além do Princípio do Prazer (1920-1996). Em ambos os textos, a ideia freudiana é de que a tarefa do psiquismo é dominar as quantidades de excitação que ingressam nele e de vinculá-las no sentido psíquico. Para Freud, existem dois tipos de catexias, uma que flui livremente e pressiona para descarga, e outra ligada. A ligação da energia significa sua mudança de um estado livre para um estado quiescente.

\footnotetext{
3 O desejo será abordado por Freud mais tarde, em A Interpretação dos Sonhos, e está em estreita relação com sua concepção da sexualidade e seu papel na formação do psiquismo.
} 
Quanto maior a capacidade de ligar a energia, maior a força vinculadora do sistema - o que está presente na concepção do ego. E, ao contrário, quanto mais baixa a força vinculadora, menos capacidade terá o psiquismo de receber um afluxo adicional de energia. Uma energia que é ligada, é retida, não corre para a descarga. Ela é investida nas vias colaterais e pode aguardar a presença do objeto para realização da ação específica (Castiel, 2019). A partir do momento que a energia livre começa a ser ligada, 0 aparelho psíquico começa a se constituir (Castiel et al., 2009) e complexizar (Ungaretti, 2013).

\section{Processo primário e secundário}

É partir das consequências dos estados de desejo e de defesa que Freud conceitua os processos primário e secundário. Assim, no texto, diz que, diante de um estado de desejo, se houver um investimento excessivo na lembrança de um objeto, colocando-se em ação a descarga, não pode haver satisfação porque o objeto não é real. Ele está presente como ideia imaginária; é, portanto, uma alucinação e gera-se um desprazer. Da mesma forma, refere-se também a experiência de dor, dizendo que $\Psi$ precisa de uma indicação que atraia a sua atenção para a possível recatexização de uma imagem mnêmica hostil e que permita evitar, por meio de catexias colaterais, a descarga e a liberação do desprazer. Pois, se a inibição éfeita a tempo, o desprazer ea defesa serão mínimos.

Ainda com relação à descarga, Freud (1985-1996) refere que é nocivo, desde o ponto de vista biológico, iniciar a descarga antes da chegada da indicação que distingue entre a percepção e a lembrança do objeto. Portanto, as catexias das lembranças desejadas não podem ir além de certa quantidade, é preciso uma indicação da realidade do objeto para a descarga. Essa indicação da realidade é proveniente de $\omega$ na medida em que, a cada percepção externa, se produz em $\omega$ uma excitação qualitativa que implica uma pequena descarga também em $\omega$, da qual chega informações a $\Psi$. É essa indicação de qualidade que $\Psi$ utiliza para saber da realidade do objeto. No entanto, se 0 objeto é fortemente catexizado, ele também produzirá a mesma indicação de realidade que acontece no caso da percepção externa. Assim, há uma falha no critério, que poderá ser evitada se a catexia de desejo se efetuar mediante uma inibição por parte do ego na medida em que essa, não sendo tão intensa, não produzirá uma indicação de qualidade em $\Psi$, diferentemente do caso da percepção externa.

Freud (1985-1996) afirma:

A catexia de desejo, levada ao ponto da alucinação, e a completa produção do desprazer, que envolve o dispêndio total da defesa, são por nós designadas como processos psíquicos primários; em contrapartida, os processos que só se tornam possíveis mediante uma boa catexia do ego, e que representam versões atenuadas dos referidos processos primários, são descritos como processos psiquicos secundários (p. 379).

Devido a isso, pode-se dizer que a abundância da catexia do objeto e o desprazer decorrente, que levam à defesa excessiva, caracterizam o processo primário. Todavia, a partir de uma transformação do processo primário, na qual se leva em conta a utilização correta da indicação da realidade do objeto, o que permite aguentar a energia sem descarregá-la (inibição por parte do ego), constitui o processo secundário.
A partir disso, percebe-se que Freud considera o psiquismo regido por princípios (inércia e constância) e processos (primário e secundário). 0 que distingue tais mecanismos é que as funções primária e secundária dizem respeito ao "funcionamento do sistema nervoso em geral ou mesmo a todo 0 organismo, enquanto a distinção entre processos primários e secundários se refere a representações e corresponde especificamente ao sistema de neurônios $\Psi^{\prime \prime}$ (Garcia-Roza, 1984, p. 57). Entendemos, também, que os processos primário e secundário referem-se às formas de circulação da energia no psiquismo como consequência dessas tendências primárias e secundárias do organismo. Além disso, é interessante perceber que, no capítulo 7 de $A$ Interpretação dos Sonhos, Freud (1900-1996) trabalha os processos como referentes aos diferentes sistemas. Assim, o processo primário como relativo ao Inconsciente, e o processo secundário como relativo ao Pré-Consciente, 0 que, de certa forma, corresponde à ideia do Projeto da existência do ego, com sua capacidade de inibição do escoamento da energia, como o lugar onde ocorre o processo secundário.

0 interessante da leitura freudiana do Projeto (1985-1996) é a ideia da complexização psíquica que ele demonstra na sua linha de argumentação, de forma que a enunciação de um conceito implica em variadas circunstâncias, 0 que leva a uma complexidade maior, e assim por diante. Um conceito dessa espécie é 0 do pensar e 0 do julgamento. Freud afirma que, se diante do desejo o objeto estiver presente ou houver inibição por parte do ego no caso de ausência, o processo se cumpre sem maiores consequências. No entanto, no caso de não estar presente ou somente em parte, haverá implicaçōes no sentido da complexidade psíquica. 0 pensar e o julgar são decorrências da não coincidência do objeto desejado e percebido. Cabe salientar que, já desde então, Freud entende como fator importante para o desenvolvimento psíquico a ausência do objeto que satisfaz.

Dessa forma, ele enuncia que juízo é um processo $\Psi$ que se torna possível através da inibição do ego, que ocorre quando há a dessemelhança entre a catexia de desejo de uma lembrança e a catexia perceptiva que Ihe seja semelhante. Nesse processo de julgar, a atitude seria a de aperfeiçoar a semelhança, convertendo-a em identidade. Assim como no julgamento e no pensamento, Freud analisa os processos primários e secundários em relação a outras questões, tais como sonho, sintoma, recalque e linguagem no decorrer do Projeto (1985-1996). Os sonhos, especificamente, terão um grande estatuto em 1900, no capítulo 7. Entendemos que a articulação econômica do Projeto, juntamente com a visão tópica do capítulo 7 , é o fundamento do edifício metapsicológico, que encontra seu terceiro ponto de vista, o dinâmico, na análise de Dora, que ocorreu em 1900.

\section{Considerações finais}

Pretendemos demonstrar, a partir da escrita deste artigo, que o estudo do Projeto (1985-1996) não se refere sóa uma questão de cultura da pré-história psicanalítica. Ainda que seja escrito em linguagem neurológica devido aos interesses de Freud na época, esse texto comporta a essência do pensamento econômico, que marca uma parte importante da metapsicologia, dada as suas consequências para o entendimento da psicopatologia e da clínica. A questão das energias circulantes em um sujeito, os investimentos e os desinvestimentos, as descargas e as complexidades psíquicas que as retenções de descarga proporcionam não só estão no fundamento da ideia de pulsão, como também no papel que a representação adquire no psiquismo. 
Ademais, a função do prazer como organizador da ação humana, o ego como lugar de contenção das excitações e a importância do outro, bem como de sua ausência para a complexidade psíquica, são conceitos psicanalíticos relevantes. Eles já estão presentes desde o Projeto e continuam fazendo parte da concepção freudiana de subjetividade até o fim de sua obra. Assim, entendemos que, mais do que uma contribuição à psicologia como ciência natural, este texto possibilita aberturas para o entendimento da constituição psíquica e do funcionamento das subjetividades, tendo, portanto, muita importância clínica.

\section{Referências}

Castiel, S. (2019). Narcisismo, pulsões e sexualidade: repercussões clínicas. São Paulo: Escuta.

Castiel, S., Pereira, C., Silveira, G., Valente, J., Jaskulsji, L., Firpo, L., Silva, R., Chies, T., Krug, U. (2009). Freud e o Projeto da psicanálise. Revista da Sociedade de Psicologia do Rio Grande do Sul, 8(1), 35-47.

Freud, S. (1996). Comunicação preliminar. In S. Freud, Edição Standard das Obras Psicológicas Completas de Sigmund Freud (Vol. 2, pp. 39-316). Rio de Janeiro: Imago. (Obra original publicada em 1893).

Freud, S. (1996). Estudos sobre a histeria. In S. Freud, Edição Standard das Obras Psicológicas Completas de Sigmund Freud. (Vol. 2, pp. 13-316). Rio de Janeiro: Imago. (Obra original publicada em 1893-1895).

Freud, S. (1996). As neuropsicoses de defesa. In S. Freud, Edição Standard das Obras Psicológicas Completas de Sigmund Freud. (Vol. 3, pp. 109-119). Rio de Janeiro: Imago. (Obra original publicada em 1894).

Freud, S. (1996). Projeto para uma psicologia científica. In S. Freud, Edição Standard das Obras Psicológicas Completas de Sigmund Freud. (Vol. 1, pp. 335-454). Rio de Janeiro: Imago. (Obra original escrita em 1895).

Freud, S. (1996). A interpretação dos sonhos. In S. Freud, Edição Standard das Obras Psicológicas Completas de Sigmund Freud. (Vol. 2, pp. 539-647). Rio de Janeiro: Imago. (Obra original publicada em 1900).

Freud, S. (1996). Sobre o narcisismo: uma introduçãa. In S. Freud, Edição Standard das Obras Psicológicas Completas de Sigmund Freud. (Vol. 14, pp. 77-81). Rio de Janeiro: Imago. (Obra original publicada em 1914).

Freud, S. (1996). 0 inconsciente. In S. Freud, Edição Standard das Obras Psicológicas Completas de Sigmund Freud. (Vol. 14, pp. 165-201). Rio de Janeiro: Imago. (Obra original publicada em 1915).

Freud, S. (1996). Além do princípio do prazer. In S. Freud, Edição Standard das Obras Psicológicas Completas de Sigmund Freud. (Vol. 18, pp. 13-75). Rio de Janeiro: Imago. (Obra original publicada em 1920).

Garcia-Rosa, L. (1984). Freud e o inconsciente (23a ed.) Rio de Janeiro: Zahar.

Gay, P. (2012). Freud: uma vida para nosso tempo (2a ed.) (D. Bottmann \& L. Meyer, Trad). São Paulo: Companhia das Letras. (Obra original publicada em 1923).

Masson, J. M. (1986). A correspondência completa de Sigmund Freud para Wilhelm Fliess 1887 - 1904. Rio de Janeiro: Imago.

Ungaretti, M. S. (2013). Projeto para uma psicologia científica: a construção do psiquismo, uma leitura inicial. Psicoterapia Psicanalítica, 15, 31-41. 